\title{
Multivariate optimization of the Kharasch-Sosnovsky allylic oxidation of olefins
}

\author{
Rubén Marín-Barrios, Francisco M. Guerra*, Ana Leticia García-Cabeza, F. Javier Moreno-Dorado, \\ Guillermo M. Massanet* \\ Departamento de Química Orgánica, Facultad de Ciencias, Universidad de Cádiz, Pol. Río San Pedro s/n, 11510 Puerto Real, Cádiz, Spain
}

\section{A R T I C L E I N F O}

\section{Article history:}

Received 12 October 2011

Received in revised form 18 November 2011

Accepted 25 November 2011

Available online 7 December 2011

\section{Keywords:}

Allylic oxidation

Olefins

Kharasch-Sosnovsky reaction

Simplex

Multivariate optimization

\begin{abstract}
A B S T R A C T
The multivariate optimization method known as simplex is applied to the Kharasch-Sosnovsky allylic oxidation of double bonds. By applying this method, the amounts of three variables (copper source, oxidant, and additive) are optimized at the same time. Under the conditions thus obtained the reaction takes place in a considerable shorter time, being the alkene the limiting reagent. These conditions are applied to some monoterpenes and sesquiterpenes leading regioselectively to the corresponding benzoate esters, opening a route to the employment of this reaction in the synthesis of more complex molecules.
\end{abstract}

(c) 2011 Elsevier Ltd. All rights reserved.

\section{Introduction}

A great interest in the development of new procedures aimed at the allylic oxidation of alkenes has arose in the synthetic community as a mean to increase the molecular complexity. ${ }^{1,2}$ This interest relies on the possibility to oxidize a saturated carbon located next to a double bond, enabling the access to remote positions located apart from the functional groups of the starting material. Nevertheless, despite the many procedures described in the literature, we still lack a general and reliable method to perform this transformation.

The Kharasch-Sosnovsky reaction ${ }^{3}$ is an interesting option to perform this type of transformation. This reaction involves the oxidation of the allylic position of an alkene by a perester in the presence of a copper or cobalt source, providing an allylic ester (Fig. 1).

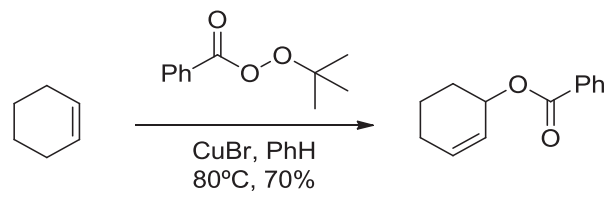

Fig. 1. Original Kharasch-Sosnovsky reaction.

This reaction has been thoroughly studied by different authors, and a plethora of conditions have been described in which the reaction proceeds mostly in moderate to good yields and enantioselectivities.

\footnotetext{
* Corresponding authors. Tel.: +34 956 016405; fax: +34 956 016393; e-mail addresses: francisco.guerra@uca.es (F.M. Guerra), g.martinez@uca.es (G.M. Massanet).
}

Nevertheless, some items remain unsolved: (i) most of the reported conditions requires the use of an excess of the alkene to be oxidized (typically 10 equiv), a fact unacceptable when the alkene is valuable, (ii) very long reaction times (from hours to weeks) are required in order to get good conversions and yields, (iii) the reaction has been rarely employed beyond methodological purposes and it has seldom been considered as a tool in complex syntheses. ${ }^{4-6}$ Its use has been restricted to the oxidation of poorly functionalized alkenes. On the positive side, the Kharasch-Sosnovsky reaction can be carried out in an enantioselective manner, and excellent enantiomeric excesses have been reported. ${ }^{7-13}$

Taking into account the potential of the Kharasch-Sosnovsky reaction and the benefits that the solving of the aforementioned problems would provide, we have undertaken the task of developing new reaction conditions that permits this reaction to be included in the selected pool of reactions commonly employed in the synthesis of complex natural products. Three main goals are sought in this work: (i) the discovery of conditions in which the alkene is the limiting reagent, (ii) the use of inexpensive conditions with regard to the copper source and the oxidant and the development of the simplest technical conditions, and (iii) the widening of the current scope in terms of the complexity of the substrate.

\section{Results and discussion}

As it is usual in this type of study we first approached the problem by keeping all variables but one constant and studying the effect of the remaining variable, following a classical univariate approach. We soon discovered that contradictory results were 
obtained, which led to us assuming that a multivariate analysis optimizing several variables at once would lead to better results as we will explain in detail below.

\subsection{Univariate approach: variable to variable optimization}

For the sake of simplicity, cyclohexene was selected as an olefin model and tert-butyl peroxybenzoate (TBPB) as an oxidant agent. The reactions were run for 24 or $48 \mathrm{~h}$ at room temperature.

An essential requisite was to employ only 1 equiv of the olefin, aiming at the application to worthy substrates. The first variable under study was the copper source. A survey of the literature displays that a wide range of copper sources can be employed ${ }^{14,15}$ and that those more suitable for the enantioselective version of the reaction are air sensitive and expensive. We decided to start reassessing the performance of the most popular copper salts (Table 1 ), using DBU since Muzart and Le Bras demonstrated that this additive increases significantly the reaction rate. ${ }^{16}$ The initial results were rather disappointing, leading to low yields. Nevertheless, since $\mathrm{CuCl}$ resulted to provide the highest yields, we decided to continue our investigation using this salt.

Table 1

Optimization of the copper source

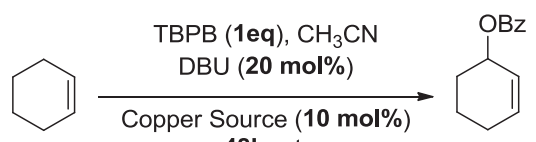

$48 h, r$.

\begin{tabular}{lc}
\hline Copper source & Yield $^{\mathrm{a}}(\%)$ \\
\hline $\mathrm{Cu}\left(\mathrm{CH}_{3} \mathrm{CN}\right)_{4}(\mathrm{OTf})$ & 5 \\
$\mathrm{Cu}\left(\mathrm{CH}_{3} \mathrm{CN}\right)_{4}\left(\mathrm{PF}_{6}\right)$ & 2 \\
$\mathrm{Cu}\left(\mathrm{CH}_{3} \mathrm{CN}\right)_{4}\left(\mathrm{BF}_{4}\right)$ & 16 \\
$\mathrm{Cu}(\mathrm{OTf}) 1 / 2 \mathrm{PhH}$ & 10 \\
$\mathrm{Cu}(\mathrm{OTf})_{2}$ & 9 \\
$\mathrm{CuCl}$ & 23 \\
$\mathrm{CuCl}$ & $19^{\mathrm{b}}$ \\
\hline
\end{tabular}

a Determined by GC analysis.

b 4 days of reaction.

It is also described in the literature that the presence of amines other than DBU, used as additives, can accelerate notably the reaction rate. ${ }^{17-22}$ According to Singh's group previous reports, ${ }^{17}$ phenylhydrazine was also tested, however this additive showed lower yields than DBU. We checked the effect of the addition of different nitrogen additives to the reaction. The results are displayed in Table 2 .

Table 2

Additive optimization

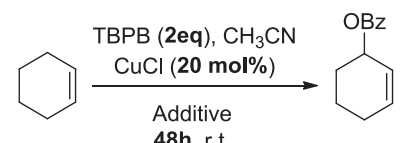

$48 \mathrm{~h}, \mathrm{r} . \mathrm{t}$

\begin{tabular}{lllc}
\hline Additive (20 mol \%) & Yield $^{\mathrm{a}}(\%)$ & Additive (20 mol \%) & Yield $^{\mathrm{a}}(\%)$ \\
\hline DBU & 100 & DBN & 47 \\
PhNHNH $_{2}$ & $33^{\mathrm{b}}$ & DBO & 1 \\
Pyrrolidine & 100 & lmidazol & 24 \\
L-proline & 80 & Hexamethylenetetramine & 1 \\
$\mathrm{Et}_{3} \mathrm{~N}$ & 67 & DMAP & 17 \\
$\mathrm{DIPEA}^{i} \mathrm{Pr}_{2} \mathrm{NH}$ & 7 & 2-(Methylamino)pyridine & 10 \\
${ }^{\mathrm{D}-V a l i n e}$ & 25 & Colidine & 5 \\
L-Tyrosine & 10 & Diphenylguanidine & 16 \\
\hline
\end{tabular}

a Determined by GC analysis.

b Yield (44\%) in acetone.
Not only DBU but also other bases, such as pyrrolidine or proline provided the corresponding esters in excellent yields. The results suggest that better $\sigma$-donors increase the reaction rate. ${ }^{23}$ Although these reactions produced high yields, they required $48 \mathrm{~h}$. The yield at $24 \mathrm{~h}$ using DBU as an additive was only $64 \%$. It was clear that further optimization was needed if we wanted to shorten the reaction time.

Furthermore, the question of whether we were using the optimal amounts of reagents or further adjustments were still needed remained unsolved. The influence of a substantial lowering either of the amounts of copper, DBU or both had to be investigated.

Consequently, we decided to perform an optimization of the stoichiometry of the reaction. Several concentrations of $\mathrm{CuCl}$ and DBU were examined. The results are shown in Table 3 . The inspection of this table shows that a minimum amount of copper and DBU is needed although a drop of the yield is observed for amounts higher than $20 \mathrm{~mol} \%$ employing only 1 equiv of TВPB. A preferential formation of different multinuclear copper species ${ }^{24}$ under these conditions could explain this outcome.

Table 3

Optimization of the catalytic charge

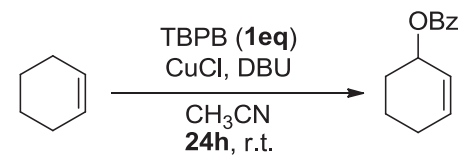

\begin{tabular}{lcc}
\hline Catalytic charge $(\mathrm{mol} \%)$ & & Yield $^{\mathrm{a}}(\%)$ \\
\hline $\mathrm{CuCl}$ & $\mathrm{DBU}$ & \\
\hline 10 & 10 & 22 \\
20 & 20 & 64 \\
20 & 40 & 49 \\
30 & 30 & 45 \\
40 & 20 & 37 \\
70 & 70 & 31 \\
100 & 100 & 17 \\
\hline
\end{tabular}

${ }^{\text {a }}$ Determined by GC analysis.

\subsection{Multivariate approach: the simplex method}

At this point, given the uncertainty that we were using reagents and reactants in the correct proportions, we decided to use a different approach. This is not so simple as many issues are involved in the outcome of this reaction. It is noteworthy to point out that the mechanism of the Kharasch-Sosnovsky oxidation is not fully known in detail. It is a complex mechanism involving free radical generation, coordination to metallic species in different oxidation states, and a concerted rearrangement. Recently Mayoral and coworkers $^{25}$ have proposed some changes to the mechanism previously reported by Zavitsas. ${ }^{26}$ An additional issue is the need to adjust the addition of the catalyst and the additive with the homolysis of the oxidant agent for an optimal performance of the catalytic cycle.

Taking into account these considerations, we carried out the optimization of three variables (amount of copper, oxidant, and additive) employing the mathematical method for multivariate optimization known as simplex, previously used by Muzart et al. in an asymmetric version. ${ }^{27,28}$

The use of the simplex method allows the optimization of the yield of a reaction by the simultaneous modification of all variables. A simplex is an $n$-dimensional figure with $n+1$ vertices, where $n$ is the number of variables to optimize. In the case of two variables it is a triangle; a tetrahedron in the case of three variables. Each vertex represents different reaction conditions. In the case of two variables, the simplex starts with three initial reaction conditions 
A, B, and C, forming a triangle (Fig. 2). Once the three reactions corresponding to such conditions have been carried out, the yields are evaluated. The experiment that leads to the lowest yield is the discarded vertex and new conditions are calculated by a reflection operation using the formula $V_{\text {new }}=2 M-V_{\text {discarded, }}$, where $V$ stands for vertex and $M$ is the average of the vertices that are kept. This process is repeated iteratively ruling out those conditions that provide the worst yields. Thus we shall achieve those reaction conditions that lead to the best results. The simplex method also provides the ability to go faster in the optimization by other operations, such as expansion or contraction of the figure when the worst experiment fulfills certain conditions. ${ }^{29}$ In this case it is called modified simplex method. The simplex method finishes when the reaction yield does not improve further.

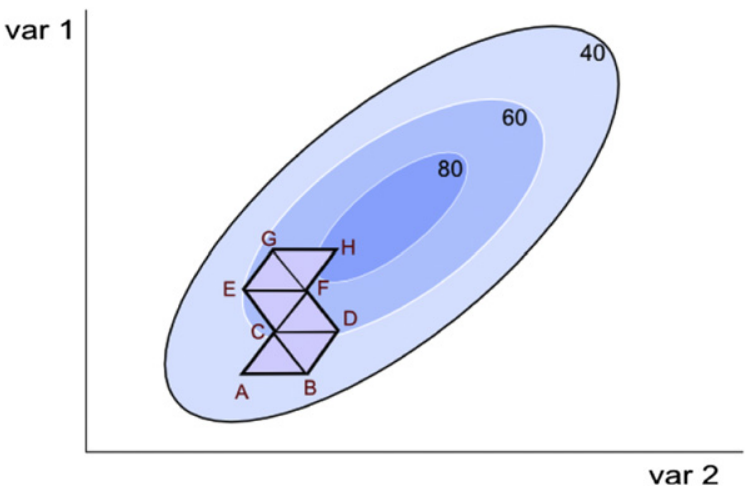

Fig. 2. Simplex optimization of a 2-variable system. The figures in the circles correspond to yields.

The optimization of the three above-mentioned variables (ТВPB, DBU, and $\mathrm{CuCl}$ equivalents) implied that the simplex was a tetrahedron. The conditions for the first four trials were set as shown in Table 4 . After 13 experiments, a $100 \%$ yield for the allylic oxidation of cyclohexene is achieved using 1 equiv of cyclohexene, 3.54 equiv TBPB, 0.49 equiv of $\mathrm{CuCl}$, and 0.29 equiv of DBU, in only $24 \mathrm{~h}$ at room temperature. Fig. 3 displays the simplex optimization process.

Table 4

Conditions and results for the simplex optimization in the case of cyclohexene

\begin{tabular}{lllll}
\hline Vertex & TBPB $^{\mathrm{a}}$ & $\mathrm{CuCl}^{\mathrm{a}}$ & $\mathrm{DBU}^{\mathrm{a}}$ & Yield $^{\mathrm{b}}(\%)$ \\
\hline 1 & 1.50 & 0.20 & 0.20 & 21 \\
2 & 2.00 & 0.20 & 0.20 & 26 \\
3 & 1.75 & 0.29 & 0.20 & 27 \\
4 & 1.75 & 0.23 & 0.28 & 23 \\
5 & 2.17 & 0.28 & 0.25 & 44 \\
6 & 2.50 & 0.32 & 0.28 & 53 \\
7 & 2.42 & 0.31 & 0.17 & 42 \\
8 & 2.44 & 0.41 & 0.24 & 70 \\
9 & 2.67 & 0.51 & 0.25 & 64 \\
10 & 1.75 & 0.29 & 0.20 & 86 \\
11 & 3.86 & 0.45 & 0.29 & 92 \\
12 & 3.45 & 0.48 & 0.37 & 72 \\
$\mathbf{1 3}$ & $\mathbf{3 . 5 4}$ & $\mathbf{0 . 4 9}$ & $\mathbf{0 . 2 9}$ & $\mathbf{1 0 0}$ \\
\hline
\end{tabular}

All the reactions were run for $24 \mathrm{~h}$. The bold means that the best result (100\% yield)

a Equivalents of each reagent.

b Determined by GC analysis.

\subsection{Application of the simplex method to other substrates}

Other more complex olefins were tested under the conditions found for cyclohexene. The yields resulted to be lower than those found in cyclohexene. Therefore, the reactions were subjected to individual optimizations following the procedure developed for cyclohexene. In all cases, the reaction time was limited to $24 \mathrm{~h}$ since no improvement was observed by increasing the time. The
Simplex optimization for cyclohexene

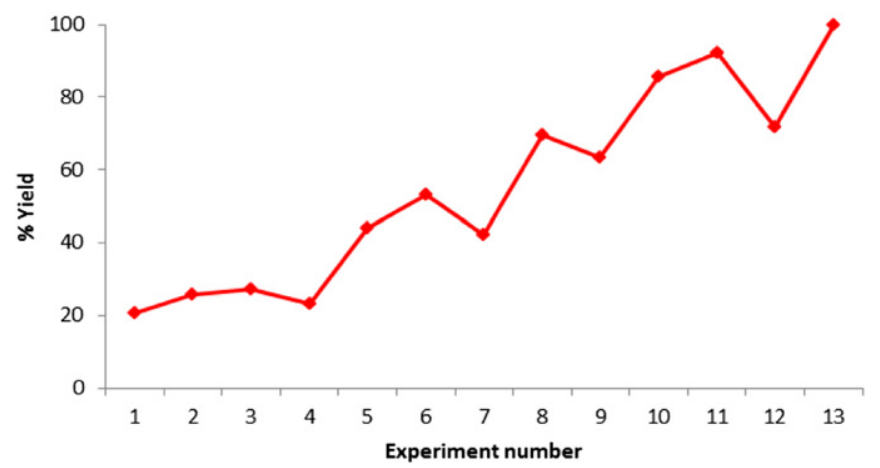

Fig. 3. Simplex optimization of cyclohexene.

reactions resulted to be regioselective and, in those cases in which the substrate is chiral, stereoselective, only a single diastereomer being isolated.

The results for the employed substrates are summarized in Table $5 .^{30}$

Table 5

Optimized conditions for the oxidation of other substrates

Substrate

${ }^{\text {a }}$ Determined by GC analysis after 1 day of reaction. All values are the media of three runs.

b Equivalents of each reagent, 1 equiv of starting material.

c $75 \%$ based on recovered starting material.

Although the yields are moderated, it is noteworthy to mention that the reaction time has been reduced compared to what is usually reported in the literature and that the yields are based on the alkene and not in the oxidant. Furthermore, our conditions employ inexpensive copper chloride at room temperature. No exclusion of moisture or drying of solvents is needed. The complexity level of the substrates employed expands the scope of the Kharasch-Sosnovsky reaction beyond the typical cycloalkenes described in the literature.

\section{Conclusions}

We have demonstrated that it is possible to carry out the efficient allylic oxidation of double bonds present not only in simple 
cycloalkenes, but also in monoterpenes and sesquiterpenes, under mild conditions, employing inexpensive $\mathrm{CuCl}$, and TBPB as an oxidant in the presence of DBU. The conditions have been optimized by employing the multivariate optimization method called simplex.

The limiting reagent is now the alkene, a fact that guarantees its applicability in worthy substrates. In addition, the reaction time has been considerably reduced, taking only $24 \mathrm{~h}$ to provide useful yields.

Although further work is required, the application to substrates other than simple cycloalkenes opens the way to the popularization of this reaction in the field of organic synthesis.

\section{Experimental section}

\subsection{General considerations}

Reactions were monitored through TLC on commercial silica gel plates. Visualization of the developed plate was performed by fluorescence quenching and/or aqueous ceric ammonium molybdate/anisaldehyde stains. GC was performed on a Perkin-Elmer Clarus GC400 using a Perkin-Elmer Elite5 column. The commercially available reagents and solvents were used without further purification. NMR spectra were recorded on a Varian Inova 400. IR spectra were recorded in a Perkin-Elmer Spectrum BX2, using $\mathrm{NaCl}$ plates, data are reported in $\mathrm{cm}^{-1}$. Mass spectra were obtained in a VG Autospec-Q.

\subsection{General procedure for allylic oxidation}

A solution of the copper source in $4 \mathrm{~mL}$ of acetonitrile is stirred and the amino additive was added. Then, the substrate $(1 \mathrm{mmol})$ and the oxidant agent, TBPB, are added. The yield is determined by GC analysis using octadecane as internal standard. After $24 \mathrm{~h}$ the reaction is worked up by adding $15 \mathrm{~mL}$ of AcOEt and extracted with $10 \mathrm{~mL}$ of saturated $\mathrm{NH}_{4} \mathrm{Cl}(\times 2)$. The aqueous layer is then extracted with $10 \mathrm{~mL}$ of dichloromethane $(\times 2)$. The organic layers are combined and dried over anhydrous $\mathrm{Na}_{2} \mathrm{SO}_{4}$. The solvent is removed under reduced pressure. The yellow oily crude is purified by column chromatography on silica gel and semipreparative HPLC.

4.2.1. 3-Phenylcyclohex-2-enyl benzoate (4). Yellow oil. ${ }^{1} \mathrm{H}$ NMR $\left(400 \mathrm{MHz}, \mathrm{CDCl}_{3}\right): \delta 8.00(\mathrm{dd}, J=8.4,1.3 \mathrm{~Hz}, 2 \mathrm{H}), 7.50-7.44(\mathrm{~m}, 1 \mathrm{H})$, 7.39-7.35 (m, 2H), 7.35-7.17 (m, 5H), $6.15(\mathrm{dt}, J=3.6,1.7 \mathrm{~Hz}, 1 \mathrm{H})$, $5.69-5.60(\mathrm{~m}, 1 \mathrm{H}), 2.52$ (dddd, $J=6.0,4.8,3.5,1.8 \mathrm{~Hz}, 1 \mathrm{H}$ ), 2.36 (dtdd, $J=9.6,7.5,3.5,1.8 \mathrm{~Hz}, 1 \mathrm{H}), 2.02-1.77(\mathrm{~m}, 4 \mathrm{H}) .{ }^{13} \mathrm{C}$ NMR $\left(101 \mathrm{MHz}, \mathrm{CDCl}_{3}\right): \delta 166.28,142.27,141.05,132.76,130.73,129.60$, $128.30,128.25,127.65,125.43,122.30,69.47,28.12,27.41,19.50$. IR (film) $\nu_{\max }\left(\mathrm{cm}^{-1}\right): 2938,1712,1450,1316,1270,1176,1111,1069$, 1026, 915, 758, 712. HR-MS $\left(\mathrm{CI}^{+}\right)$, calcd for $\mathrm{C}_{19} \mathrm{H}_{18} \mathrm{O}_{2} 278.1307$, found 273.1301 .

4.2.2. Benzoyloxylimonene (6). Colorless oil. ${ }^{1} \mathrm{H}$ NMR $(400 \mathrm{MHz}$, $\mathrm{CDCl} 3$ ): $\delta 8.08$ (dd, $J=8.4,1.4 \mathrm{~Hz}, 2 \mathrm{H}), 7.58-7.53(\mathrm{~m}, 1 \mathrm{H}), 7.47-7.42$ (m, 2H), 5.86-5.75 (m, 1H), 5.59-5.50 (m, 1H), 4.80-4.68 (m, 2H), 2.49-2.37 (m, 1H), 2.31-2.27 (m, 1H), 2.27-2.22 (m, 1H), 2.11 (ddd, $J=14.2,4.1,2.4 \mathrm{~Hz}, 1 \mathrm{H}), 1.99-1.87(\mathrm{~m}, 1 \mathrm{H}), 1.78-1.75(\mathrm{~m}, 3 \mathrm{H})$, 1.75-1.73 (m, 3H). ${ }^{13} \mathrm{C}$ NMR (101 MHz, $\left.\mathrm{CDCl}_{3}\right): \delta$ 166.30, 148.58, 132.75, 131.03, 130.66, 129.57, 128.26, 127.88, 109.20, 71.19, 35.99, 33.76, 30.92, 20.85, 20.67. IR (film) $\nu_{\max }\left(\mathrm{cm}^{-1}\right): 2932,1714,1450$, $1314,1268,1110,1025,711 .[\alpha]_{\mathrm{D}}^{20}-8.6\left(c 0.025, \mathrm{CHCl}_{3}\right)$. HR-MS $\left(\mathrm{Cl}^{+}\right)$: calcd for $\mathrm{C}_{17} \mathrm{H}_{20} \mathrm{O}_{2} 256.1463$, found 256.1458 .

4.2.3. Benzoyloxypinene (8). Colorless oil. ${ }^{1} \mathrm{H}$ NMR (400 MHz, $\left.\mathrm{CDCl}_{3}\right): \delta 8.04(\mathrm{dd}, J=8.4,1.4 \mathrm{~Hz}, 2 \mathrm{H}), 7.57-7.52(\mathrm{~m}, 1 \mathrm{H}), 7.46-7.40$ (m, 2H), 5.66 (dq, $J=4.4,1.4 \mathrm{~Hz}, 1 \mathrm{H}), 4.70$ (q, $J=1.6 \mathrm{~Hz}, 2 \mathrm{H}), 2.43$ (dt, $J=8.7,5.6 \mathrm{~Hz}, 1 \mathrm{H}), 2.36-2.32(\mathrm{~m}, 1 \mathrm{H}), 2.30$ (ddd, $J=4.4,3.0,1.6 \mathrm{~Hz}$, $1 \mathrm{H}), 2.22(\mathrm{td}, J=5.6,1.5 \mathrm{~Hz}, 1 \mathrm{H}), 2.13(\mathrm{dtd}, J=8.7,2.9,1.4 \mathrm{~Hz}, 1 \mathrm{H}), 1.30$ $(\mathrm{s}, 3 \mathrm{H}), 1.24(\mathrm{~d}, J=8.7 \mathrm{~Hz}, 1 \mathrm{H}), 0.88(\mathrm{~s}, 3 \mathrm{H}) .{ }^{13} \mathrm{C} \mathrm{NMR}(101 \mathrm{MHz}$ $\left.\mathrm{CDCl}_{3}\right): \delta 166.39,142.96,132.75,130.41,129.50,128.27,121.59$ 67.45, 43.63, 40.71, 38.07, 31.46, 31.25, 26.11, 21.11. IR (film) $\nu_{\max }$ $\left(\mathrm{cm}^{-1}\right): 3034,2832,1719,1451,1366,1270,1176,1111,1070,1026$ 800, 711. $[\alpha]_{\mathrm{D}}^{20}-28.7\left(\right.$ c $\left.0.072, \mathrm{CHCl}_{3}\right)$. HR-MS $\left(\mathrm{CI}^{+}\right)$: calcd for $\mathrm{C}_{17} \mathrm{H}_{20} \mathrm{O}_{2} 256.1463$, found 256.1461 .

4.2.4. Benzoyloxyvalencene (10). Yellow oil. ${ }^{1} \mathrm{H}$ NMR $(400 \mathrm{MHz}$, $\left.\mathrm{CDCl}_{3}\right): \delta 8.06(\mathrm{dd}, J=8.4,1.4 \mathrm{~Hz}, 2 \mathrm{H}), 7.56-7.51(\mathrm{~m}, 1 \mathrm{H}), 7.43(\mathrm{t}$, $J=7.5 \mathrm{~Hz}, 2 \mathrm{H}$ ), 5.59 (d, $J=5.1 \mathrm{~Hz}, 1 \mathrm{H}$ ), 5.38 (ddd, $J=7.0,4.0,2.0 \mathrm{~Hz}$, $1 \mathrm{H}), 4.72-4.71(\mathrm{~m}, 2 \mathrm{H}), 2.37(\mathrm{tdt}, J=14.1,4.5,2.1 \mathrm{~Hz}, 1 \mathrm{H}), 2.28(\mathrm{tt}$, $J=12.6,3.1 \mathrm{~Hz}, 1 \mathrm{H}), 2.20$ (ddd, $J=14.3,4.2,2.6 \mathrm{~Hz}, 1 \mathrm{H}), 1.94(\mathrm{dt}$, $J=12.9,2.8 \mathrm{~Hz}, 1 \mathrm{H}), 1.86-1.80(\mathrm{~m}, 2 \mathrm{H}), 1.74(\mathrm{t}, J=1.0 \mathrm{~Hz}, 3 \mathrm{H})$, $1.38-1.03(\mathrm{~m}, 4 \mathrm{H}), 0.96(\mathrm{~s}, 3 \mathrm{H}), 0.93(\mathrm{~d}, J=6.6 \mathrm{~Hz}, 3 \mathrm{H}) .{ }^{13} \mathrm{C} \mathrm{NMR}$ $\left(101 \mathrm{MHz}, \mathrm{CDCl}_{3}\right): \delta 166.25,150.94,150.04,132.59,131.00,129.56$ $128.18,117.67,108.61,68.45,44.42,40.53,38.15,35.80,33.04,32.44$, $32.40,20.85,16.85,15.08$. IR (film) $\nu_{\max }\left(\mathrm{cm}^{-1}\right): 2926,1718,1450$ $1313,1269,1175,1109,888,712 .[\alpha]_{\mathrm{D}}^{20}+148\left(c 0.043, \mathrm{CHCl}_{3}\right)$. HR-MS $\left(\mathrm{CI}^{+}\right)$: calcd for $\mathrm{C}_{22} \mathrm{H}_{28} \mathrm{O}_{2} 324.2089$, found 324.2085 .

\section{Acknowledgements}

We are grateful to Junta de Andalucía for the financial support. R.M.B. acknowledges the Universidad de Cádiz for a fellowship. We thank Dr. José Ma Palacios for his guidance with multivariate optimization, Dr. Juan Antonio Poce for his simplex software, and Ms. Lindsey Ray for her helpful assistance.

\section{References and notes}

1. Andrus, M. B. In Science of Synthesis, Stereoselective Synthesis Allylic and Benzylic Oxidation; Georg Thieme Verlag: Stuttgart, Germany, 2011; Vol 3, pp 469-482.

2. Harschneck, T.; Kirsch, S. F. Nachr. Chem. 2010, 58, 36-39.

3. Kharasch, M. S.; Fono, A. J. Org. Chem. 1958, 23, 324-325.

4. Andrus, M. B.; Lashley, J. C. Tetrahedron 2002, 58, 845-866.

5. Eames, J.; Watkinson, W. Angew. Chem., Int. Ed. 2001, 40, 3567-3571.

6. Andrus, M. B.; Zhou, Z. J. Am. Chem. Soc. 2002, 124, 8806-8807.

7. Gokhale, A. S.; Minidis, A. B. E.; Pfaltz, A. Tetrahedron Lett. 1995, 36, 1831-1834

8. Andrus, M. B.; Argade, A. B.; Chen, X.; Pamment, M. G. Tetrahedron Lett. 1995, 36 2945-2948.

9. Kawasaki, K.; Tsumura, S.; Katsuki, T. Synlett 1995, 1245-1246.

10. DattaGupta, A.; Singh, V. K. Tetrahedron Lett. 1996, 37, 2633-2636.

11. Ginotra, S. K.; Singh, V. K. Org. Biomol. Chem. 2006, 4, 4370-4374.

12. Andrus, M. B.; Asgari, D. Tetrahedron 2000, 56, 5775-5780.

13. Zhou, J.; Tang, Y. Chem. Soc. Rev. 2005, 34, 664-676.

14. Andrus, M. B.; Chen, X. Tetrahedron 1997, 53, 16229-16240.

15. Tan, Q.; Hayashi, M. Adv. Synth. Catal. 2008, 350, 2639-2644.

16. Le Bras, J.; Muzart, J. J. Mol. Catal. A: Chem. 2002, 185, 113-117.

17. Sekar, G.; DattaGupta, A.; Singh, V. K. J. Org. Chem. 1998, 63, 2961-2967.

18. Malkov, A. V.; Bella, M.; Langer, V.; Kocovsky, P. Org. Lett. 2000, 2, 3047-3049

19. Lee, W. S.; Kwong, H. L.; Chan, H. L.; Choi, W. W.; Ng, L. Y. Tetrahedron: Asymmetry 2001, 12, 1007-1013.

20. Bolm, C.; Frison, J. C.; Le Paih, J.; Moessner, C. Tetrahedron Lett. 2004, 45 , 5019-5021.

21. Ramalingan, B.; Neuburger, M.; Pfaltz, A. Synthesis 2007, 572-582.

22. Hoang, V. D. M.; Reddy, P. A. N.; Kim, T. J. Organometallics 2008, 27, 1026-1027.

23. Sekar, G.; DattaGupta, A.; Singh, V. K. Tetrahedron Lett. 1996, 37, 8435-8436.

24. Le Bras, J.; Muzart, J. Tetrahedron: Asymmetry 2003, 14, 1911-1915.

25. Mayoral, J. A.; Rodríguez-Rodríguez, S.; Salvatella, L. Chem.-Eur. J. 2008, 14, 9274-9285.

26. Beckwith, A. L. J.; Zavitsas, A. A. J. Am. Chem. Soc. 1986, 108, 8230-8234

27. Betteridge, D.; Wade, A. P.; Howard, A. G. Talanta 1985, 32, 709-722.

28. Levina, A.; Muzart, J. Tetrahedron: Asymmetry 1995, 6, 147-156.

29. For a more detailed explanation of the modified simplex method, applied to an organic reaction, see: Chubb, F. L.; Edward, J. T.; Wong, S. C. J. Org. Chem. 1980, $45,2315-2320$.

30. Isolated yields for $(R)$-limonene (5) and $(S)$ - $\beta$-pinene (7) were only around $30 \%$ due to volatility issues. In the case of valencene $(\mathbf{9})$, a $75 \%$ of isolated yield was obtained after recovery of unreacted starting material. 